\title{
Analisis Stabilitas Lereng Tiga Dimensi
}

\author{
Dwitya Okky Azanna* \\ Fakultas Teknik Sipil Universitas Batanghari Jambi \\ *Correspondence email: dwitya.okky.azanna@mail.unbari.ac.id
}

\begin{abstract}
Abstrak. Stabilitas lereng ditinjau untuk mengetahui kestabilan terhadap lereng tersebut, pengaruh kemiringan, cuaca, beban berlebih, serta gempa menjadi penyebab kelongsoran. Perlu ditinjau berbagai cara untuk mencegah itu terjadi, dengan cara melakukan beberapa pemodelan pemograman. Pemodealan tidak hanya bisa dilakukan secara metode dua dimensi, tetapi dengan perkembangan jaman bisa juga dilakukan dengan pemodelan tiga dimensi. Hasil dari pemodealan tersebut yaitu menghasilkan nilai angka keamanan, hanya saja apakah efektif dan kompleks hasil akhir yang dihasilkan dari masing-masing pemodelan. Penelitian ini membandingkan analisis stabilitas lereng dua dimensi dan tiga dimensi, dimana nilai angka keamanan yang didapatkan bahwa tiga dimensi lebih besar dari dua dimensi. Hal ini terjadi karena jika menggunakan kondisi parameter yang sama, dan pelebaran dari geometri dua dimensi, dimana batas dari bidang gelincir telah ditentukan dari pemodelannya, maka hasil yang didapatkan tidak akan berbeda jauh, namun kita bisa mengetahui volume runtuhan tanah tersebut.
\end{abstract}

Kata Kunci : stabilitas lereng, dua dimensi, tiga dimensi

\section{PENDAHULUAN}

Kestabilan lereng di setiap wilayah sangat perlu diperhatikan karena akan berhubungan dengan keamanan dari wilayah tersebut. Lereng yang mengalami kelongsoran tidak hanya karena kemiringannya saja, tetapi juga kondisi dari beberapa faktor seperti karakteristik parameter tanah, dan tentunya kondisi luar seperti beban yang berlebih, intensitas hujan, serta akibat adanya gempa. Oleh karena itu perlu adanya analisis stabilitas lereng sehingga bisa mengurangi potensi longsor dan membahayakan masyarakat di sekitarnya. Analisis stabilitas lereng pada umumnya menggunakan pemodelan analisis dua dimensi metode elemen hingga. Hasil yang didapatkan cukup untuk mengetahui angka keamanan dari lereng tersebut, tetapi seringkali tidak mewakili terhadap asumsi kondisi perkuatan dan kondisi geometri aslinya. Oleh karena itu banyak yang menggunakan metode analisis tiga dimensi sebagai analisis pemodelan. Perlu diperhatikan apa saja perbedaan dari analisis tiga dimensi dengan dua dimensi yang telah dilakukan. Pada hasil analisis tesis azanna, 2019 dapat dilihat bahwa nilai faktor aman hasil analisis tiga dimensi memiliki nilai lebih besar dari satu jika dibandingkan dengan analisis pemodelan dua dimensi, dimana faktor aman kondisi tingkat ketidakpastian analisis yang dikategorikan tinggi dikarenakan kondisi geologi kompleks yaitu 1,5.

\section{METODE}

Faktor-faktor atau penyebab yang mempengaruhi gerakan massa tanah sebagai pemicu terjadinya gerakan tanah yaitu dianalisis kestabilitas lereng didasarkan pada konsep kesetimbangan batas plastis (limit plastic equilibrium), teori batas plastis dan metode numerical seperti metode elemen hingga. Angka keamanan didefinisikan sebagai perbandingan antara gaya yang menahan dengan gaya yang menggerakkan, dimana faktor kuat geser tersebut diambil lebih besar atau sama dengan 1,2 sampai 1,5.

$\mathrm{SF}=\frac{\tau}{\tau \mathrm{d}}$

dengan :

$\mathrm{SF} \quad=$ angka keamanan (Safety factor)

$\tau \quad=$ tahanan geser tanah (kuat geser yang tersedia)

rd = tegangan geser tanah (tegangan geser yang terjadi)

Metode elemen hingga menggunakan pengurangan kuat geser, sedangkan metode kesetimbangan batas menggunakan perbandingan antara gaya-gaya yang menahan lereng terhadap gaya-gaya yang bekerja. Kondisi stabilitas lereng yang direncanakan disesuaikan dengan kondisi pembebanan statis dan pembebanan dinamis yang dapat terjadi dilapangan.

Pada desain perencanaan, metode yang digunakan merupakan kondisi analisis numerik. Metode analisis numerik ini terbagi menjadi konsep kesetimbangan batas dan metode elemen hingga. Desain yang dilakukan bisa menggunakan dua dimensi maupun tiga dimensi. Metode analisis numerik berupa konsep kesetimbangan batas dilakukan dengan persamaan kesetimbangan Bishop (1955), Force Equilibrium (1960), Janbu (1968), Morgenstern dan Price (1965) dan Spencer (1967). Sedangkan pendekatan metode elemen hingga merupakan analisis stabilitas lereng yang lebih kompleks. Hasil analisis yang didapatkan berupa tegangan dan regangan yang sifatnya elastis material, beragam massa tanah dan bentuk geometri. 
1. Pemodelan Dua dimensi

Pemodelan yang dilakukan yaitu penentuan bidang gelincir secara umum dengan menggunakan auto locate dan terhadap titik yang ditinjau menggunakan entry and exit. Masing-masing model ini dianalisis dengan persamaan kesetimbangan Ordinary/Fellenius, Bishop, Janbu, Morgenstern dan Price. Pada penelitian ini pemodelan dilakukan dengan bantuan Program Slope/W dan Plaxis. Pemodelan yang dilakukan dengan mennetukan bidang gelincir secara auto locate terhadap titik yang ditinjau.

2. Pemodelan Tiga Dimensi

Metode Limit Equilibrium adalah metode yang menggunakan prinsip kesetimbangan gaya, metode ini juga dikenal dengan metode irisan karena masa tanah longsor dari lereng tersebut dipecah-pecah menjadi beberapa irisan vertikal. Metode Irisan pada metode batas analisis ekuilibrium yaitu Massa tanah yang tidak stabil terbagi menjadi serangkaian slide vertikal dan permukaan slip bisa berbentuk lingkaran atau poligonal. (Whitman dan Bailey,1967)

Gaya-gaya yang bekerja tiap irisan ini terdiri dari gaya geser dan gaya normal efektif di sepanjang sisi irisannya, dan juga resultan gaya geser efektif dan resultan gaya normal efektif yang bekerja di sepanjang dasar irisan. Terdapat dua asumsi bidang kelongsoran yaitu berbentuk circular dan non-circular. Metode yang banyak digunakan untuk bidang gelincir circular adalah Fellenius dan Bishop serta untuk bidang gelincir non-circular digunakan Janbu, Spencer, Morgenstern dan Price.

Metode yang paling umum untuk mendefinisikan angka keamanan adalah;

1. Moment equilibrium method digunakan untuk analisis longsor rotasi dengan permukaan slip melingkar;

$\mathrm{SF}=\frac{M_{r}}{M_{d}}$

2. Force equilibrium method diterapkan untuk menganalisis kegagalan translasi atau rotasi yang mempertimbangkan permukaan berbentuk plane atau polygonal;

$\mathrm{SF}=\frac{F_{r}}{F_{d}}$

Dengan;

$\mathrm{SF} \quad=$ angka keamanan (Safety factor)

$M_{r} \quad$ = Jumlah momen penahan

$M_{d} \quad=$ Jumlah momen pendorong

$F_{r} \quad=$ Jumlah gaya penahan

$F_{d} \quad=$ Jumlah gaya pendorong

\section{HASIL DAN PEMBAHASAN}

Tipe slip surface yang digunakan oleh system pemrograman akan menentukan bidang gelincir suatu lereng saat terjadi longsor sangat berpengaruh terhadap analisisnya. Hasilnya menunjukan bahwa rasio $\mathrm{SF}_{3} / \mathrm{SF}_{2}$ cukup sensitif terhadap parameter tanah $\mathrm{c}$ dan $\phi$, serta bentuk dasar dari permukaan geser. Namun, angka keamanan tiga dimensi umumnya jauh lebih tinggi dari angka keamanan dua dimensi, meskipun dalam beberapa situasi memang tidak demikian. Studinya juga menunjukkan bahwa tanah longsor di tanah kohesif dapat mengikuti geometri geser permukaan lebar, mendekati kasus 2D.

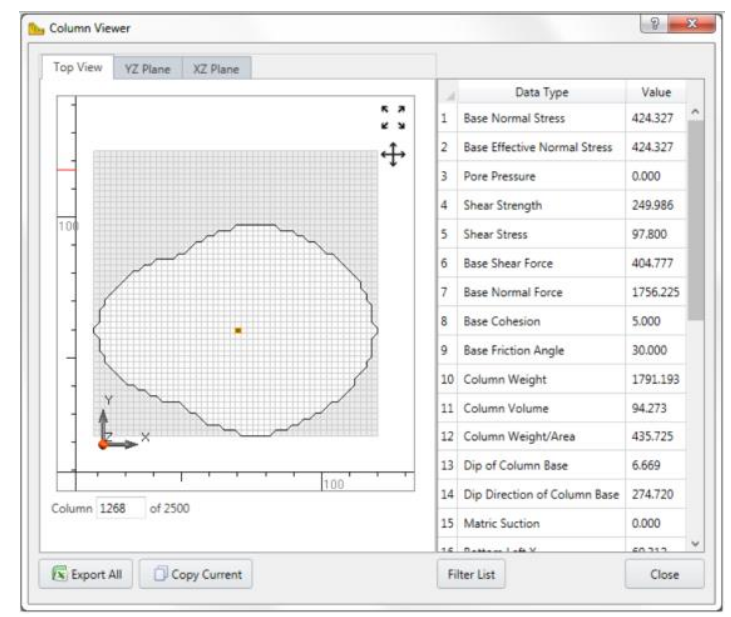

Gambar 1. Interpretasi Pemodelan menggunakan Pemograman RockScience 
Pada slide lainnya di tanah yang kohesi, mungkin mengikuti permukaan tipe tiga dimensi. Beberapa ringkasan sebagai berikut;

1. Pilihan metode sangat tergantung pada jenis kegagalannya untuk menganalisis masalah stabilitas lereng.

2. Beberapa analisis stabilitas kemiringan dua dimensi yang umum digunakan disajikan secara singkat dan paling sederhana.

3. Metode kesetimbangan batas pada analisis tiga dimensi sejauh ini terbatas pada input data yang sangat sederhana seperti geometri, kondisi tanah dan tidak dapat memperhitungkan kondisi air. Hal ini dikarenakan pengembangan analisis tiga dimensi menggunakan data-data analisis dari dua dimensi.

4. Metode elemen hingga lebih unggul untuk membatasi metode keseimbangan batas karena kekuatan membentuk geometri yang kompleks dan rumit, kondisi air, serta banyak nilai parameter tanah yang harus diisikan kedalam software pemrograman agar bisa mempertimbangkan hubungan tegangan-regangan dari tanah. Oleh karena itu, metode elemen hingga jauh lebih rumit untuk digunakan dibandingkan metode batas ekuilibrium.
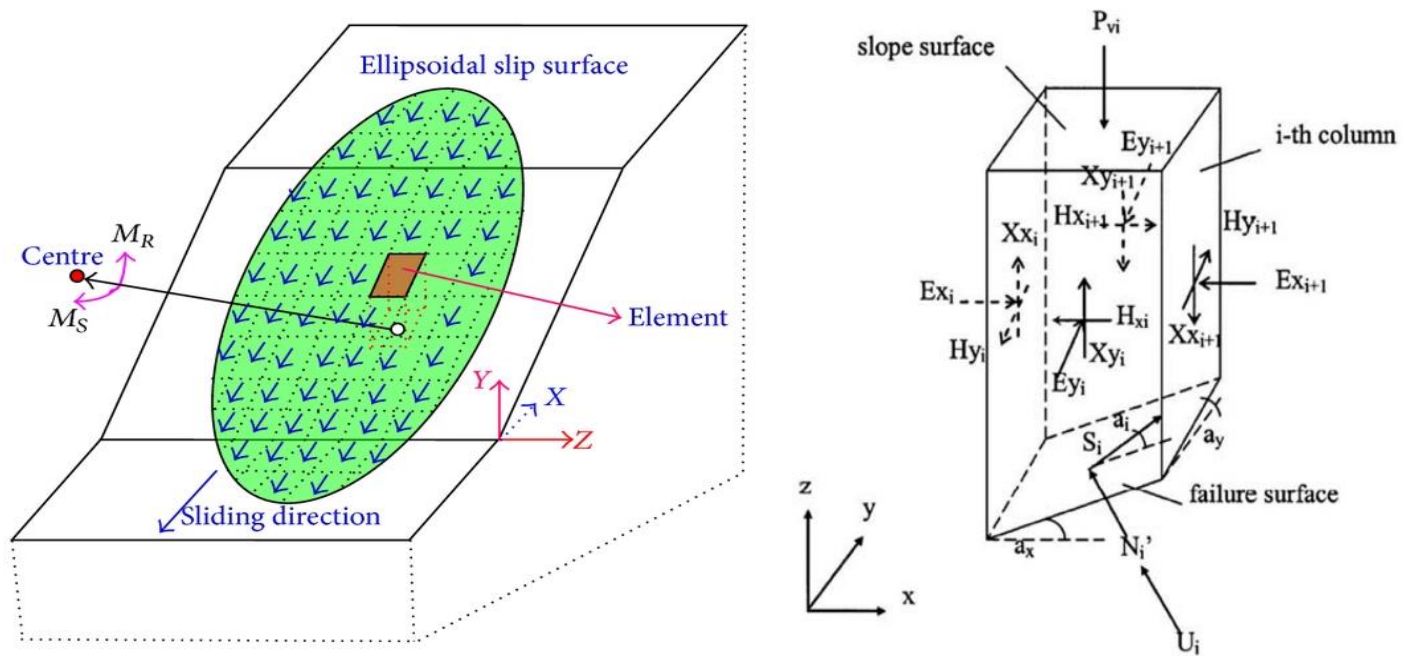

Gambar 2. Bidang Sliding dan Arah Gaya Lereng Tiga Dimensi

Analisis perhitungan yang digunakan menggunakan kriteria keruntuhan Mohr Coulomb dengan menggunakan dua Metode yaitu Metode Bishop dan Metode Janbu. Kesetimbangan moment pada metode ini mengabaikan gaya gesek antar irisan, dimana gaya normal cukup untuk mendefinisikan gaya-gaya antar irisan dengan menjumlahkan gaya-gaya dalam arah vertikal. Metode Janbu menganalisis nilai faktor aman berdasarkan kesetimbangan gaya dengan menjumlahkan gaya-gaya pada kesetimbangan horizontal. Gaya pada suatu model lereng tidak hanya dijumlahkan pada arah vertikal, namun juga dijumlahkan pada arah horizontal.

Hasil analisis dari $3 \mathrm{~d} / 2 \mathrm{~d}>1$. Tegangan geser yang terjadi di sepanjang bidang longsor tiga dimensi berasal dari segala arah sehingga gaya tahan ini lebih besar untuk menahan gaya dorongnya, jika dibandingkan dengan nilai dua dimensi akan mendapatkan nilai yang lebih besar. Pada analisis dua dimensi gaya tahan yang terjadi hanya berasal dari satu arah, hal ini dibuktikan dengan tipe irisan pada pemrograman yang digunakan.

Longsoran tanah yang umumnya terjadi membentuk bidang longsoran berupa cekungan, sehingga digunakan dalam analisis pemrograman dengan bentuk kelongsoran berupa cekungan atau lekungan guna mempermudah hitungan analisis stabilitasnya secara matematik. Metode tiga dimensi yang dikembangkan sangat terbatas pada masalah yang sederhana seperti geometri, kondisi tanah dan kondisi air yang tidak rumit.

Analisis tiga dimensi menjadi penting untuk digunakan sebagai analisis angka keamanan jika kondisi geometri sangat kompleks sehingga sulit untuk menentukan bagian slip surface pada analisis dua dimensi. Geometri lereng dan permukaan slip yang berfariasi secara signifikan pada arah lateral, sifat materialnya sangat tidak homogen atau anisotropik, kemiringan secara lokal, kemiringan dengan kekuatan geser yang rumit dan tekanan air pori yang memerlukan penggabungan efek geometri lereng dan kekuatan geser untuk menentukan arah gerakan yang mengarah ke faktor keamanan minimum, atau untuk kembali menghitung kekuatan geser dari kemiringan yang gagal. Dalam situasi seperti ini, analisis tiga dimensi sangat mungkin diperlukan.

Tingkat ketidakpastian kondisi analisis dikategorikan rendah atau tinggi tergantung pada pemodelan geometri. Pengaruh pemodelan menjadi hal paling kompleks dalam pemodelan bidang tiga dimensi, dimana kondisi geologi yang bisa dipahami atau kompleks, kondisi tanah seragam atau bervariasi, penyelidikan tanah yang konsisten, lengkap dan logis terhadap kondisi nyata di lapangan.

Dari hasil analisis tersebut dapat dilihat bahwa nilai faktor aman tiga dimensi lebih besar dibandingan analisis dua dimensi. Semakin kompleks kekuatan tanah pada lereng yang ditinjau menyebabkan efek yang lebih besar terhadap analisis tiga dimensi. Sehingga analisis pada tiga dimensi bisa digunakan jika analisis komplek dan sangat 
mendetail untuk ditinjau agar menghasilkan nilai angka keamanan yang lebih mendekati dengan kondisi nyata di lapangan.

Asumsi utama dari hasil metode kegagalan blok pada stabilitas lereng tiga dimensi yaitu masalahnya adalah geometri menjadi simetris dikarenakan data yang digunakan berdasarkan geometri pada pemodelan dua dimensi yang kemudian dianggap linear, sehingga terdefenisi permukaan tanahnya dan lapisan tanah secara lateral terus menerus sama sepanjang geometri yang digunakan. Permukaan bidang geser menjadi sama sehingga diambil titik lemah pada area bidang longsor. Batasan antara blok aktif dan sentral, blok pasif dan sentral vertikal tidak ada kekuatan geser di sepanjang batas ini. Hal tersebut menyebabkan angka keamanan sama di seluruh permukaan kegagalan.

Dalam analisis slide rotasi, parameter tanah diasumsikan homogen dan permukaan kegagalan tiga dimensi terdiri dari silinder terpusat pada bidang semi ellipsoid. Pada tipe kegagalan rotasi tersebut dibagi menjadi banyak kolom vertikal dengan arah gerakan yaitu sepanjang bidang X-Y saja (tidak ada gerakan dalam arah Z), maka pada saat kegagalan tegangan geser terjadi sepanjang bidang Y-Z diasumsikan nol, gaya geser antar kolom sejajar dengan dasar kolom, distribusi tegangan normal antar kolom diasumsikan linier dengan kedalaman, sehingga diasumsikan kekuatan interslice sama di seluruh massa kegagalan.

Berdasarkan hasil tersebut, masalah static determinate untuk faktor yang dihitung dari angka aman, kekuatan dan momen ekuilibrium dipenuhi untuk setiap kolom serta untuk massa total. Analisis Chen menyimpulkan bahwa efek tiga dimensi lebih signifikan pada panjang yang lebih kecil dari massa kegagalan, hal ini membenarkan hasil dari analisis ini dimana batas bidang longsor yang ditentukan menyebabkan nilai angka keamanan yang sama. Pengaruh kelandaian lereng efek tiga dimensi paling signifikan untuk tanah dengan nilai kohesi tinggi dan sudut geser rendah, serta tekanan air pori dapat menyebabkan efek tiga dimensi menjadi lebih besar.

\section{SIMPULAN}

Analisis dari perencanaan dua dimensi menghasilkan nilai yang tidak jauh berbeda dengan tiga dimensi, hal ini dikarenakan nilai yang diinput dan kemudian dianalisis berdasarkan data yang sama. Analisis nilai keamanan minimum didapatkan dari sistem yang diprogramkan secara otomatis mencari slip surface minimum yang berbentuk circular, jika pemrograman dilakukan secara manual, data-data yang perlu diinput sangat detail dan akan selesai pada waktu yang cukup lama untuk mendapatkan nilai angka keamanan. Pemrograman menggunakan analisis pemodelan tiga dimensi sangat efektif digunakan jika mempunyai data hasil penyelidikan tanah yang kompleks agar bisa memodelkan geometri sesuai dengan kondisi di lapangan.

\section{DAFTAR PUSTAKA}

Azanna, D.O. 2019. Analisis Stabilitas Lereng Tiga Dimensi Akibat Penambahan Beban Infrastruktur Kawasan Situs Candi Ratu Boko.: Thesis, Jurusan Teknik Sipil dan Lingkungan, Fakultas Teknik, Universitas Gadjah Mada.

Chen, R. H. (1981): “Three-dimensional slope stability analysis," Joint Highway Research Project, Eng. Experiment station, Purdue University, Report JHRP-81-17

Chen dan Chameau (1983) Chen, R. H. and Chameau, J. L. (1983): "Three-dimensional limit equilibrium analysis of slopes," Geotechnique, Vol. 32, No. 1, pp. 31-40

Hardiyatmo, H. C. 2012. Tanah Longsor dan Erosi. Yogyakarta: Gadjah Mada University Press.

Putra, A.O. 2017. Analisis Stabilitas Lereng Tanah di Atas Batuan Breksi Pada Pengembangan Infrastruktur Situs Ratu Boko Yogyakarta.: Thesis, Jurusan Teknik Sipil dan Lingkungan, Fakultas Teknik, Universitas Gadjah Mada.

SNI (Standar Nasional Indonesia). 2017. Persyaratan Perancangan Geoteknik : 8460:2017. Jakarta : Badan Standarisasi Nasional

Whitman RV, Bailey WA (1967) Use of computers for slope stability analysis, ASCEJ Geotech Eng Div 93(4):475498 